\title{
The effect of two different attachments with implant retained mandibular overdentures on the masticatory function
}

\begin{abstract}
Statement of problem: The improvement of the oral function of implant retained mandibular overdentures may depend on the degree of retention and stability of the denture and thus on the type of attachment.
\end{abstract}

Purpose of the study: The aim of the study was to evaluate of the effect of two different attachment designs with different resiliency of implant retained mandibular overdentures on the masticatory function.

Methods: Twelve completely edentulous patients were selected for the study each patient received two interforaminal implants in the canine areas of the mandible using standardized two-stage surgical technique. Implants were left unloaded for three months. Six of the patients received implant overdenture with ball and socket attachment first then the same denture was modified to receive positioner attachment. The other six patients received the implant overdenture with positioner first then the same denture was modified to receive ball and socket. Muscle activity and maximum muscle activity of both temporalis and masseter muscles were recorded during chewing cake, peanut and during clenching with using the electromyography.

Results: Muscle activity and maximum muscle activity showed higher results with the positioner attachment in both masseter and temporalis muscles although the difference was not statistically significant. Masseter muscle showed higher results in both types of the attachments.

Conclusion: The positioner attachment might be selected over Ball \& Socket attachment when designing a two implant retained mandibular overdentures since it is more superior from the masticatory function point of view.

Keywords: implant overdenture, positioner, ball and socket, masticatory function, electromyography
Volume 4 Issue 2 - 2016

\author{
Ahmed M Abdelhamid,' Nayouz A Metwally, ${ }^{2}$ \\ Mohammed $\mathrm{H}_{\text {Imam }}^{3}$ \\ Alexandria University, Egypt
}

\section{Correspondence: Nayrouz Adel Metwally, Assistant lecturer, Department of Removable Prosthodontics, Alexandria} University, Egypt, Email dr_nayrouz@hotmail.com

Received: November 26, 2015 | Published: February II, 2016
Abbreviations: EMG, electromyography; GF, gram force; RMS, root mean square value; MBF, maximum biting force

\section{Introduction}

Patients with severely resorbed mandibles often experience problems with their conventional complete dentures especially with regard the mandibular ones. The main complaints of these patients are lack of optimal stability and retention of their mandibular dentures. ${ }^{1}$ This in return may negatively affect functional ability such as speech, aesthetics and chewing ability. ${ }^{2,3}$ The recent development of Osseo integrated implants has broadened the treatment options that are available to edentulous patients. ${ }^{4}$ Patients report positive outcomes in satisfaction, masticatory function and quality of life after receiving implant-retained prostheses. ${ }^{5}$

The acceptance of mandibular implant-retained overdentures has become so overwhelming that according to McGill Consensus Statement, ${ }^{6}$ and more recently in the York Consensus Statement. ${ }^{7}$ on Overdentures, a two-implant overdenture should become the standard of care for edentulous mandible.

Ball attachments are considered the simplest type of attachments for clinical application with tooth- or implant-supported overdentures. ${ }^{8}$ In comparison to the bar/clip attachment overdenture, ball attachments may be less costly, less technique sensitive, less dependent on implant position, easier to clean and to replace, easier to adjust and to control the amount of retention, may require less inter arch space, and are better able to distribute functional forces. ${ }^{9}$

The newly developed locator attachment system has become widely applied. Though, there are only a few in vitro studies concerning the evaluation of this system and according to Kleis et al. ${ }^{11}$ until 2010 there is no in-vivo study of this attachment system available. ${ }^{10,11}$ Recently, the locator attachment system being characterized by a low profile design, ease of seating in the oral cavity by the patient, self-locating feature to fit non-parallel implants up to $40^{\circ} \mathrm{C}$ divergence have been advocated as a suitable alternative to the classical widely used ball attachment. ${ }^{12}$ Other studies have reported that locator attachment system possessed the highest retentive force and maintained that force up to $30^{\circ}$ tilting when compared to ball system. ${ }^{13}$

The combination of a mandibular implant-supported or retained overdenture and maxillary conventional complete denture provides significant improvement in masticatory performance compared to complete dentures in both the mandible and maxilla for a limited population having persistent functional problems with an existing mandibular complete denture due to severely resorbed mandible. ${ }^{14}$ 
Muscle activity of the masseter and temporalis muscles is a measure of the force exerted during mastication. ${ }^{15}$ Muscle activity during mastication can be objectively evaluated by recording the surface electromyography (EMG) of jaw muscle. ${ }^{16}$

In this study we examined the hypothesis that more retention and stability of the denture improves the masticatory function, provided that the retention and stability of the overdenture mainly depend on the attachment system used. The present study aimed at evaluation of the influence of two different attachment designs on the muscle activity during chewing and maximum muscle activity during clenching.

\section{Materials and methods}

\section{Patient selection criteria and allocation}

This study has utilized twelve completely edentulous patients conducted in the Removable Prosthodontics Department, Faculty of Dentistry, Alexandria University. The patients enrolled in this study were with a mean age of 50 years (range: $40-60 \mathrm{yr}$ ), non-smokers, free from any intra-oral or systemic diseases, had class I maxillomandibular relationships, with good oral hygiene and they were selected with enough basal bone height and width for placement of 2 piece implants. Prior to any treatment approach every patient was thoroughly evaluated regarding both dental and medical status. The Ethics Committee of the Alexandria University approved the protocol. Written informed consent was obtained from each patient after a full explanation of the clinical trial.

\section{Surgical and prosthetic procedures}

A set of complete maxillary and mandibular denture was fabricated for every patient according to standardized conventional technique. Radiographic evaluation by $\mathrm{CBCT} \cdot{ }^{17}$ (J. Morita, Veraview R100, Japan) was done for each patient using radiographic-surgical template; a clear auto-polymerized (Auto-cure acrylic resin, Acrostone, England) duplicate of the prefabricated mandibular complete denture to determine the width, length and angulation of the implant (Figure $1 \mathrm{a} \& \mathrm{~b})$. In the interforaminal area (canine region) of the mandibular arch, two implants (Superline, Dentium, Korea, 3.6mm in diameter, $10 \mathrm{~mm}$ in length) were placed, one in the left side canine region and other in right side canine region, using a flap technique, ${ }^{18}$ according to a standardized two-stage protocol. ${ }^{19}$ The patient was left for 3 months as a healing period for optimal osseointegration to occur. Every patient was instructed to make regular visit every month to reline the old denture with soft liner (Acrostone Co, England). After three months, the implants were uncovered by small crestal incisions at the location of the implants. The cover screws were removed and the healing abutments were placed for one week for the gingiva to heal.

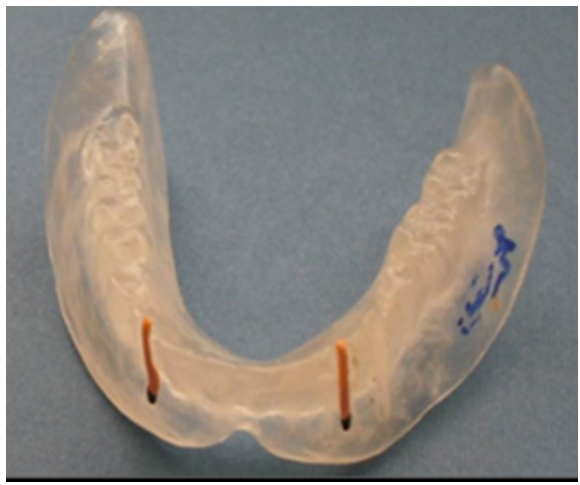

Figure Ia Radiographic surgical template.

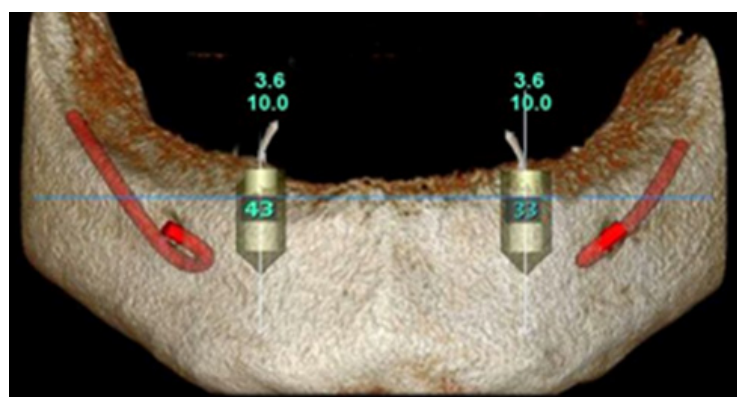

Figure Ib CBCT image presenting the ideal size and angulation for the implant.

A new set of dentures was made. Stabilizing and connecting the attachments to the existing mandibular complete denture was performed by direct pick-up technique. The ball abutment (BAB352018, Dentium Co.Ltd, Korea.) selected to this study was with $3.5 \mathrm{~mm}$ diameter and with $2 \mathrm{~mm}$ collar height, while the selected female socket (BPF3, Dentium Co.Ltd, Korea) was the one which provide from $300 \mathrm{gf}$ to $500 \mathrm{gf}$ retention force and the positioner (Positioner abutment, L13D102811, Dentium Co.Ltd, Korea) selected for this study was low profile $(2 \mathrm{~mm})$ collar height with $3.5 \mathrm{~mm}$ diameter with a socket set(Positioner socket set FSMHS, Dentium Co.Ltd, Korea), The nylon caps of the were changed from ivory (300gf retention) to orange (500gf retention) to blue (1000gf highest retention) within one month The patient was instructed to wear the denture for 2 weeks before the evaluation of the muscle activity.

\section{Evaluation of muscle activity using (EMG)}

Six of the patients received implant overdenture with ball and socket attachment (Figure 2\&3) first then the same denture was modified to receive positioner attachment (Figure $4 \& 5$ ). The other six patients received the implant overdenture with positioner first then the same denture was modified to receive ball and socket.

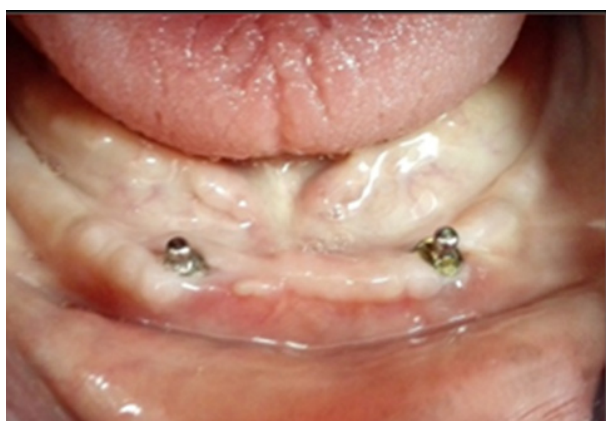

Figure 2 Mini ball abutment was located on the implants.

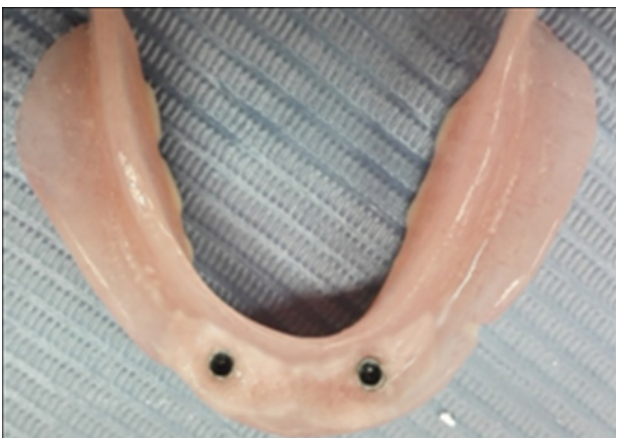

Figure 3 The denture with socket in the fitting surface. 


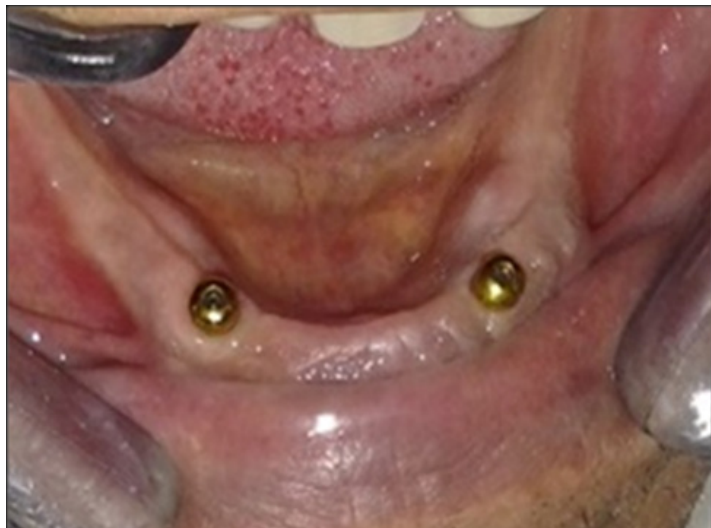

Figure 4 Locator (Positioner) attachments were fixed in place.

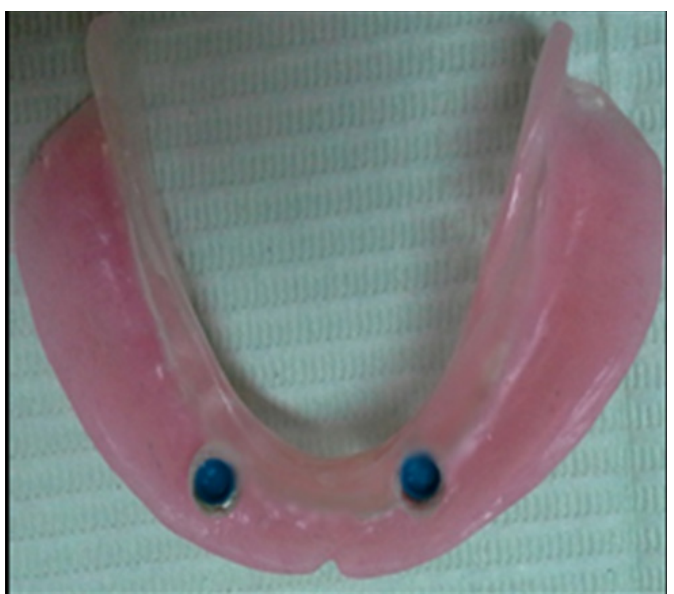

Figure 5 Positioner socket with blue colored cap.

Recordings were made by EMG device (Nicolet-Viking-Quest, San Diego, CA, USA) after the complete absence of any discomfort, when patients are presumed to be adapted to their dentures. During all recordings, the patients were seated with their head unsupported and were asked to maintain a naturally erect position. The masseteric myoelectric activity of both sides (left and right) was recorded by means of bipolar electrode positioned on the bellies of the muscles parallel to the fiber orientation with interelecrtode distance $15 \mathrm{~mm}$ apart (Figure $6 \mathrm{a} \& \mathrm{~b}$ ). An electrode on the palm of the patient served as a ground reference. Electro conductive gel (Ten20, D.O.Weaver and Co, 565-B Nucla way, Aurora, Co 80011, UK) was used on the electrode before contacting the skin. The patient was instructed to clench with preformed silicon index (Zetaplus Zhermack, Badia, Polesine, Italy) between the teeth to measure the maximum biting force (MBF) then he was instructed to chew on specific amount of peanut $(1 \mathrm{gm})$ for ten seconds intervals and finally to chew on piece of cake for ten seconds intervals. The previous tasks were separated by 2 minutes resting period. The same procedure was repeated with temporalis muscle of both sides (left and right). The EMG signals were amplified and sampled at $1500 \mathrm{~Hz}$. The data comprised the gross values' root mean square (RMS) of the EMG signal collected during the exam. Two weeks rest period was permitted between the use of one attachment and the other where healing abutments were repositioned and overdenture was replaced by the old denture which was relived opposite to the healing abutment.

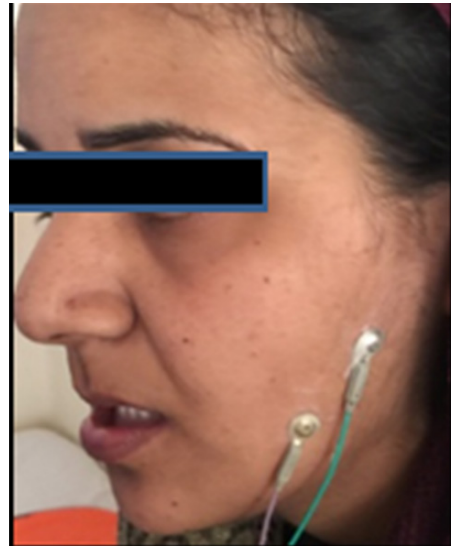

Figure 6a Bipolar electrode positioned on the bellies of the massetric muscles.

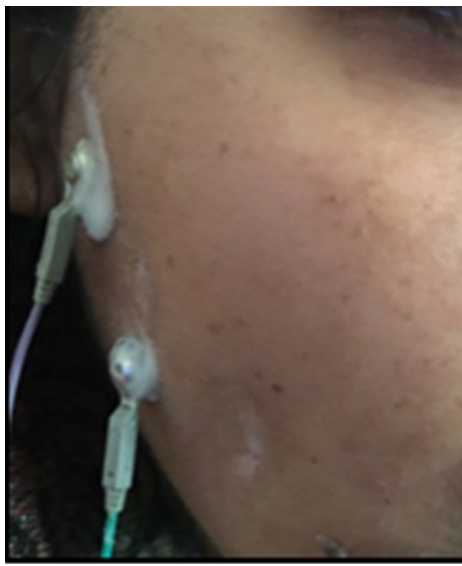

Figure $\mathbf{6 b}$ Bipolar electrode positioned on the bellies of the temporalis muscles.

\section{Results}

\section{Statistical analysis}

Comparison between two independent data was done using independent t-test, while the paired t-test was used to analyze two paired data. Comparison between multiple data was done using ANOVA and Post Hoc test which were assessed using adjustedBonferroni. Significance test results were quoted as two-tailed probabilities. Significance of the obtained results was judged at the $5 \%$ level. A p-value of less than 0.05 was considered statistically significant.

\section{Comparison between the two attachments according to EMG measurements (RMS values) of the masseter muscle}

In the right side of the masseter muscle, The positioner (locator) attachment has shown lower RMS values on chewing a piece of cake, peanut and clenching with silicon index than the ball and socket attachment However, the difference between both attachments was not statistically significant. While In the left side of the masseter muscle, the positioner (locator) attachment has shown higher RMS values on chewing a piece of cake, peanut and clenching with silicon index than the ball and socket attachment. The difference was only statistically significant on chewing cake and on clenching with silicon index $(\mathrm{p} \leq 0.05)$ (Table 1\& Graph 1). 
Table I Comparison between the two attachments according to EMG measurements (RMS values) of the masseter muscle

\begin{tabular}{|c|c|c|c|c|}
\hline & \multicolumn{2}{|l|}{$\begin{array}{l}\text { Ball and Socket } \\
(n=\mid 2)\end{array}$} & \multicolumn{2}{|l|}{$\begin{array}{l}\text { Positioner } \\
(n=\mid 2)\end{array}$} \\
\hline & Right & Left & Right & Left \\
\hline \multicolumn{5}{|l|}{ Cake } \\
\hline Min.-Max. & $28.0-66.0$ & $23.0-60.0$ & $28.0-46.0$ & $39.0-85.0$ \\
\hline Mean $\pm S D$. & $40.33 \pm 13.77$ & $44.25 \pm 12.89$ & $36.92 \pm 5.66$ & $62.58 \pm|7.4|$ \\
\hline Median & 35.50 & 46.0 & 37.50 & 67.0 \\
\hline$t(p)$ & $\longrightarrow$ & $\longleftarrow$ & \multicolumn{2}{|c|}{$\begin{array}{c}0.795(0.439) \\
2.931 *(0.008 *)\end{array}$} \\
\hline \multicolumn{5}{|l|}{ Peanut } \\
\hline Min. - Max. & $26.0-63.0$ & $35.0-101.0$ & $28.0-58.0$ & $44.0-108.0$ \\
\hline Mean \pm SD. & $48.42 \pm 11.66$ & $58.050 \pm 22.4 \mid$ & $41.58 \pm 9.42$ & $71.92 \pm 20.34$ \\
\hline Median & 51.0 & 53.0 & 41.0 & 72.0 \\
\hline$t(p)$ & & $\leftarrow$ & $(0.129)$ & $36(0.139)$ \\
\hline \multicolumn{5}{|c|}{ Silicon Index } \\
\hline Min. - Max. & $38.0-157.0$ & $33.0-69.0$ & $42.0-137.0$ & $36.0-91.0$ \\
\hline Mean \pm SD. & $100.92 \pm 41.93$ & $51.58 \pm 11.02$ & $77.42 \pm 34.16$ & $66.92 \pm 19.39$ \\
\hline Median & 105.50 & 52.0 & 65.0 & 68.0 \\
\hline$t(p)$ & & $\leftarrow$ & $2.382^{*}$ & $(0.029 *)$ \\
\hline
\end{tabular}

t, Student t-test.

*: Statistically significant at $\mathrm{p} \leq 0.05$

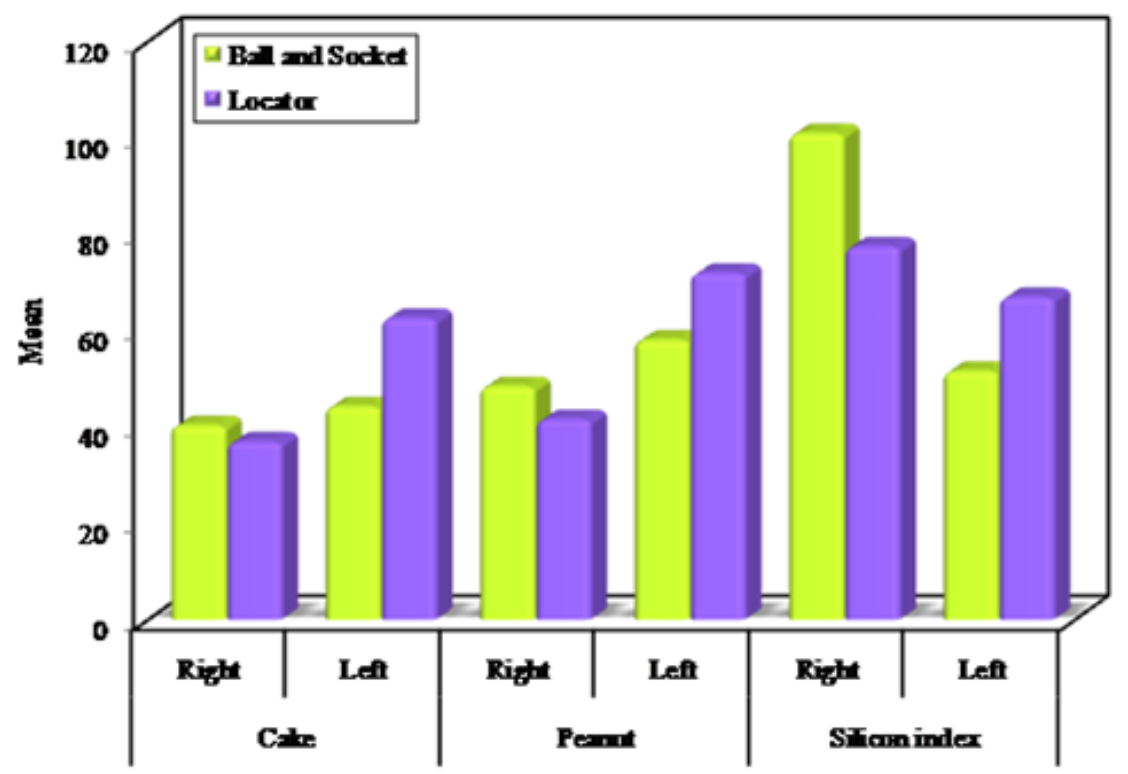

Graph I Comparison between the two attachments according to EMG measurements (RMS values) of the masseter muscle. 


\section{Comparison between the two attachments according to EMG measurements (RMS values) of the temporalis muscle}

In the right side of the temporalis muscle, the positioner (locator) attachment has shown higher RMS values on chewing a piece of cake, chewing peanut and clenching with silicon index than the ball and socket attachment. The difference between both attachments was only statistically significant on chewing cake $(\mathrm{p} \leq 0.05)$.
In the left side of the temporalis muscle, The positioner attachment has shown higher RMS values of the left temporalis muscle during chewing a piece of cake, chewing peanut and clenching with silicon index than the ball and socket attachment. The difference between both attachments was statistically significant on chewing cake and on chewing peanut $(\mathrm{p} \leq 0.05)$ (Table $2 \&$ Graph 2$)$.

Table 2 Comparison between the two attachments according to EMG measurements (RMS values) of temporalis muscle

\begin{tabular}{|c|c|c|c|c|}
\hline & \multicolumn{2}{|c|}{$\begin{array}{l}\text { Ball and Socket } \\
(n=12)\end{array}$} & \multicolumn{2}{|l|}{$\begin{array}{l}\text { Positioner } \\
(n=\mid 2)\end{array}$} \\
\hline & Right & Left & Right & Left \\
\hline \multicolumn{5}{|l|}{ Cake } \\
\hline Min.-Max. & $32.0-70.0$ & $28.0-70.0$ & $36.0-82.0$ & $37.0-80.0$ \\
\hline Mean $\pm S D$. & $45.25 \pm 12.12$ & $47.0 \pm 12.86$ & $65.42 \pm 6.96$ & $58.67 \pm 14.04$ \\
\hline Median & 42.0 & 50.0 & 70.0 & 55.50 \\
\hline$t(p)$ & & $\leftarrow$ & & $\begin{array}{l}3.352^{*}\left(0.003^{*}\right) \\
2 *\left(0.003^{*}\right)\end{array}$ \\
\hline \multicolumn{5}{|l|}{ Peanut } \\
\hline Min. - Max. & $70.0-78.0$ & $38.0-64.0$ & $25.0-88.0$ & $42.0-83.0$ \\
\hline Mean $\pm S D$. & $45.08 \pm 18.72$ & $50.42 \pm 10.18$ & $57.67 \pm 23.69$ & $62.08 \pm 13.22$ \\
\hline Median & 41.50 & 47.50 & $\begin{array}{l}56.50 \\
1.444(0.163)\end{array}$ & 63.50 \\
\hline$t(p)$ & & & & $2 *\left(0.024^{*}\right)$ \\
\hline \multicolumn{5}{|c|}{ Silicon Index } \\
\hline Min.-Max. & $23.0-120.0$ & $26.0-95.0$ & $42.0-137.0$ & $36.0-91.0$ \\
\hline Mean $\pm S D$. & $60.75 \pm 30.51$ & $53.75 \pm 22.57$ & $69.67 \pm 33.34$ & $66.83 \pm 20.73$ \\
\hline Median & 55.50 & 52.50 & 63.0 & 73.0 \\
\hline$t(p)$ & & $\leftarrow$ & $0.684(0.50 \mathrm{I})$ & $(0.153)$ \\
\hline
\end{tabular}

$\mathrm{t}$, Student t-test

*: Statistically significant at $p \leq 0.05$

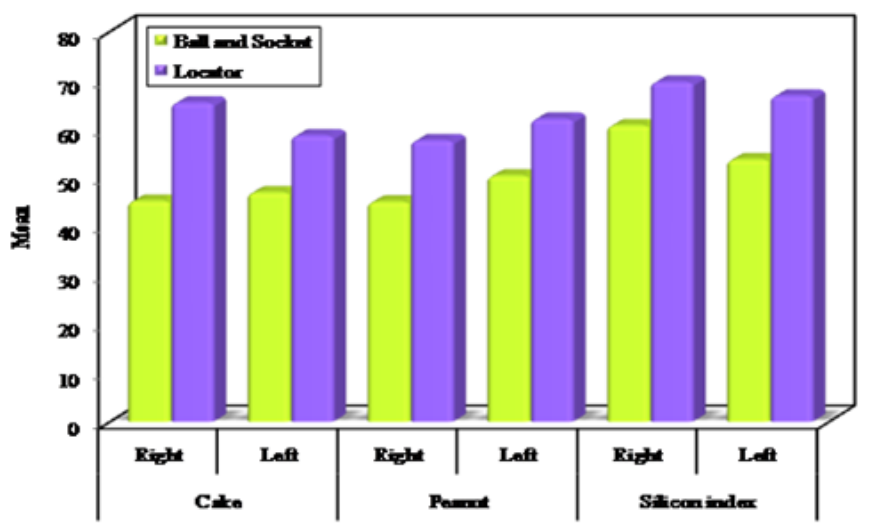

Graph 2 Comparison between the two attachments according to EMG measurements (RMS values) of the temporalis muscle. 


\section{Comparing the masseter and temporalis muscles}

In case of ball and socket attachment: The masseter muscle (both right and left sides) showed higher RMS values than the temporalis muscle. The difference between both muscles was only statistically significant on the right side.
In case of positioner attachment: The Right masseter muscle showed lower RMS value than the right temporalis muscle. The difference between both muscles was statistically significant $(\mathrm{p} \leq 0.05)$. The left masseter muscle showed higher RMS value than the left temporalis muscle. However, the difference between both muscles was not statistically significant (Table 3\& Graph 3).

Table 3 Comparison between the masseter and temporalis muscles according to EMG measurements for all testing media using different types of attachments

\begin{tabular}{|c|c|c|c|c|}
\hline & \multicolumn{2}{|c|}{$\begin{array}{l}\text { Masseter muscle } \\
(n=12)\end{array}$} & \multicolumn{2}{|c|}{$\begin{array}{l}\text { Temporalis muscle } \\
(\mathrm{n}=\mathrm{I})\end{array}$} \\
\hline & Right & Left & Right & Left \\
\hline \multicolumn{5}{|c|}{ Ball and Socket } \\
\hline Min.-Max. & $26.0-157.0$ & $23.0-101.0$ & $20.0-120.0$ & $26.0-95.0$ \\
\hline Mean \pm SD. & $63.22 \pm 37.37$ & $51.44 \pm 16.82$ & $50.36 \pm 22.46$ & $50.39 \pm 15.89$ \\
\hline Median & 51.50 & 51.50 & 45.50 & 50.0 \\
\hline $\mathbf{p}$ & & $\leftarrow$ & $\begin{array}{r}0.049 * \\
\longrightarrow\end{array}$ & \\
\hline \multicolumn{5}{|l|}{ Positioner } \\
\hline Min. - Max. & $28.0-137.0$ & $36.0-108.0$ & $25.0-137.0$ & $36.0-91.0$ \\
\hline Mean \pm SD & $51.97 \pm 27.23$ & $67.14 \pm 18.93$ & $64.25 \pm 25.33$ & $62.53 \pm 16.23$ \\
\hline \multirow[t]{2}{*}{ Median } & 42.0 & 71.0 & 64.0 & 65.0 \\
\hline & $\leftarrow$ & & & $0.032^{*}$ \\
\hline $\mathbf{p}$ & & $\longleftarrow$ & & 0.227 \\
\hline
\end{tabular}

P, $\mathrm{P}$ value for Paired; $\mathrm{t}$, test for comparing between Masseter muscle and Temporalis muscle

*: Statistically significant at $\mathrm{p} \leq 0.05$

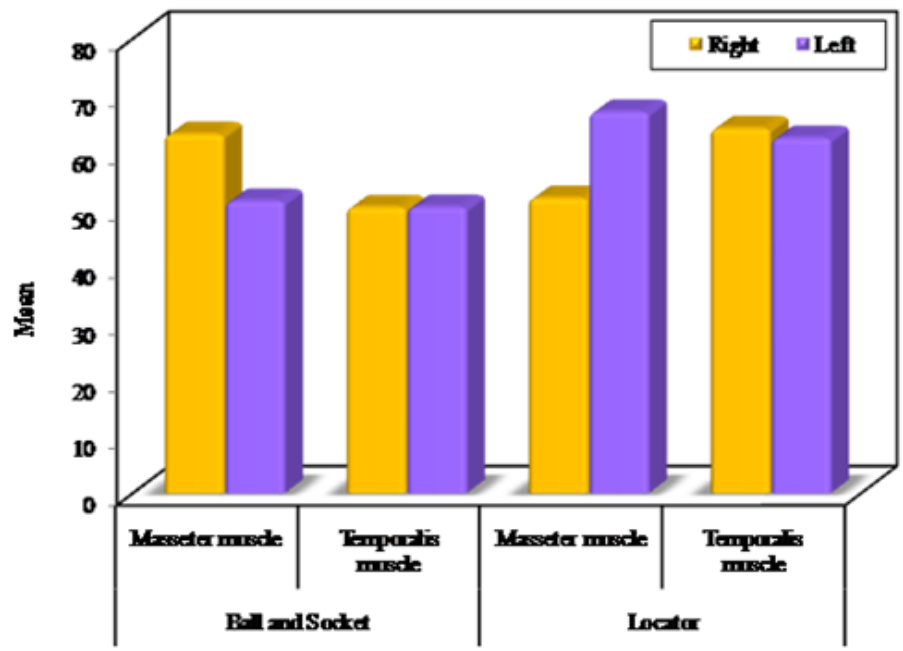

Graph 3 Comparison between masseter and temporalis muscles in both types of attachments.

\section{Discussion}

Muscle activity of the masticatory muscles can exactly reflect a patient's masticatory function and efficiency. ${ }^{20}$ The treatment with dentures retained or supported by mandibular implants has shown considerable improvements on masticatory efficiency in many studies. ${ }^{21-24}$ The patients rehabilitated with conventional complete upper dentures and lower overdenture retained by two implants showed higher masticatory efficiency indexes, approximately $50 \%$ greater than those patients rehabilitated with conventional complete dentures. ${ }^{25}$ This was explained by Fontijn-Tekamp. ${ }^{26}$ who assured that the presence of the attachments that stabilize the denture, reduce the pain and allow the patient to exert higher bite forces during function will consequently produce higher chewing efficiency.

It was reported that muscle activity was not significantly affected by different attachment types, in vander Bilts. ${ }^{14}$ research, 18 patients received 2 implants-retained mandibular overdentures with 3 different 
attachment modalities: a magnet, a ball, and a bar-clip attachment. Kampen et al. ${ }^{27}$ also reported small differences in muscle activity were found among the 3 attachment types: ball, bar and magnets. A recent systematic review by Kim et al. ${ }^{28}$ indicated that the treatment effect with mandibular implant overdenture is not related to attachment system. Elsayed et al. ${ }^{29}$ found also no significant difference in chewing efficiency using chewing gum and EMG between ball attachment and bar in two implant retained prostheses. Xu Sun. ${ }^{30}$ and Cheng et al. ${ }^{31}$ studied the masticatory efficiency of implant overdentures retained by locator and magnet attachments and the results showed no difference between both types of the attachments. In contrary to the present study in which the results showed high muscle activity of the masseter and temporalis muscles with the positioner (locator) attachment than the ball and socket attachment, this may be attributed to the high retention obtained by positioner (locator) attachment compared to all other attachments as locator provides dual retention that affect the retention and stability of the prosthesis and consequently the masticatory function of the patient. Agreed with Shady et al.$^{32}$ who compared the retention and masticatory efficiency of the bar-clip versus bar-locator attachments for retaining two implant retained complete mandibular overdentures, and concluded that the bar-locator attachment providing better long term masticatory efficiency.

Bilhan et al. ${ }^{33}$ studied the influence of three attachments; locator, ball and bar on the MBF by using a strain gauge device and they concluded that the attachment type did not influence the MBF as pointed by Uçankale et al. ${ }^{34}$ who studied the effect of both ball and bar attachments on MBF performed by biting on silicon index and recorded by EMG. In contrary to the present study in which the maximum biting force was recorded in both locator and ball attachments and the results showed higher recordings with locator attachment. However, this increase was not statistically significant. In the current study, masseter muscle showed higher records of muscle during chewing and clenching in both types of attachments than the temporalis muscle. However, the difference was not statistically significant. This study is in line with the study of Bakke et al. ${ }^{35}$ who studied the effect of implant overdenture on the maximum biting force of both masseter and temporalis muscles and recorded no significant difference. Sobhy et al. ${ }^{36}$ also used the EMG to evaluate the function of temporalis and masseter muscles with different attachment sizes and recorded no difference between both muscles.

\section{Conclusion}

With the limitations of this study regarding the sample size and short study periods, it was concluded that the combination of a mandibular implant overdenture and maxillary conventional complete denture provided significant improvement in chewing function and comfort compared to complete dentures. Both studied attachment systems were successful and useful however, the Positioner (locator) attachment might be selected over Ball \& Socket attachment when designing a two implant retained mandibular overdentures since it is more superior from the masticatory function point of view. The masseter muscle showed higher muscle activity when compared with the temporalis muscle in both types of the attachments.

\section{Funding}

None.

\section{Acknowledgements}

None.

\section{Conflicts of interest}

Authors declare that there is no conflict of interest.

\section{References}

1. Hutton JE, Heath MR, Chai JY, et al. Factors related to success and failure rates at 3-year follow-up in a multicenter study of overdentures supported by Branemark implants. Int J Oral Maxillofac Implants. 1995;10(1):3342.

2. Block MS, Almerico P, Crawford C, et al. Bone response to functioning implants in dog mandibular alveolar ridges augmented with distraction osteogenesis. Int J Oral Maxillofac Implants. 1998;13(3):342-351.

3. Fazili M, van Waas MAJ, Houwing NH, et al. Long term results of vestibule-plasty of the mandible. Int J Oral Surg. 1981;10(Suppl 1):7782.

4. Heydecke G, Locker D, Awad MA, et al. Oral and general health-related quality of life with conventional and implant dentures. Community Dent Oral Epidemiol. 2003;31(3):161-168.

5. Feine JS, Carlsson GE. Implant overdentures. The standard of care for edentulous patients. Quintessence:Chicago;2003.

6. Shor A, Goto Y, Shor K. Mandibular Two Implant Retained Over denture: Prosthetic Design and Fabrication Protocol. Compen Contin Educ Dent. 2007;28(2):80-89.

7. Thomason JM, Feine J, Exley C, et al. Mandibular two implant-supported overdentures as the first choice standard of care for edentulous patientsthe York Consensus Statement. Br Dent J. 2009;207(4):185-186.

8. Becerra G, MacEntee M. Aclassification of precision attchments. $J$ Prosthet Dent. 198758(3):322-327.

9. Sadowsky SJ. The implant-supported prosthesis for the edentulous arch: design considerations. J Prosthet Dent. 1997;78(1):28-33.

10. Buttel AE, Buhler NM, Marinello CP. Locator or ball attachment: a guide for clinical decision making. Schweiz Monatsscher Zahnmed. 2009;119(9):901-918.

11. Kleis WK, Kämmerer PW, Hartmann S, et al. A Comparison of Three Different Attachment Systems for Mandibular Two-Implant Over dentures: One-Year Report. Clin Implant Dent Relat Res. 2010;12(3):209218.

12. Eltaftazani I, Moubarak A, El-Anwar. Locator attachment versus ball attachment: 3-dimensional finite element study. 88th ed. Barcelona: Spain; 2010.

13. Chikunov I, Doan P, Vahidi F. Implant retained partial over denture with resilient attachments. J Prosthodont. 2008;17(2):141-148.

14. Van Kampen FM, Van der Bilt A, Cune MS, et al. Masticatory function with implant supported overdentures. J Dent Res. 2004;83(9):708-711.

15. Ottenhoff FM, van der Bilt A, van der Glas HW, et al. The relationship between jaw elevator muscle surface electromyogram and simulated food resistance during dynamic conditions in man. J Oral Rehabil. 1996;23(4):270-279.

16. Slagter AP, Bosman F, van der Glas HW, et al. Human jaw elevator muscle activity and food comminution in the dentate and edentulous state. Arch Oral Biol. 1993;38(3):195-205.

17. Hatcher DC. Operational principles for cone-beam computed tomography. Journal of the American Dental Association. 2010;141(Suppl 3):S3-S6.

18. Wood DL, Hoag PM, Donnenfeld OW, et al. Alveolar crest reduction following full and partial thickness flaps. J Periodontol. 1972;43(3):141144. 
19. Taylor TD, Wiens J, Carr A. Evidence-based considerations for removable prosthodontic and dental implant occlusion: a literature review. J Prosthet Dent. 2005;94(6):555-560.

20. Farias Neto A, Pereira BM, Xitara RL, et al. The influence of mandibular implant-retained overdentures in masticatory efficiency. Gerodontology. 2012;29(2):e650-e655.

21. Ellis JS, Levine A, Bedos C, et al. Refusal of implant supported mandibular over dentures by elderly patients. Geriodontology. 2011;28(1):62-68.

22. Pan YH, Lin TM, Liang CH. Comparison of Patient's Satisfaction with Implant supported Mandibular Overdentures and Complete Dentures. Biomed. 2014;J 37(3):156-162.

23. Ju-Hee H, Gyu-Un J, Sang-Wan S, et al. A prospective study of patient satisfaction after implant supported mandibular overdenture treatment in fully edentulous patients. J Korean Acad Prosthodont. 2015;53(1):1-8.

24. Tao Cheng, Li Ma, Xi Ling L, et al. Use of a single implant to retain mandibular overdenture: A preliminary clinical trial of 13 cases. Journal of Dental Sciences. 20127(3):261-266.

25. Laner BR, Cesar B, Selma S, et al. Bite force and masticatory efficiency in individuals with different oral rehabilitations. Journal of Stomatology. 2012;2(1):21-26

26. Fontijn-Tekamp FA, Slagter AP, van der Bilt A, et al. Biting and chewing in overdentures, full dentures, and natural dentitions. J Dent Res. 2000;79(7):1519-1524.

27. Van Kampen FM, van der Bilt A, Cune MS, et al. The Influence of Various Attachment Types in Mandibular Implant-retained Overdentures on Maximum Bite Force and EMG. J Dent Res. 2002;81(3):170-173.

28. Kim HY, Lee JY, Shin SW, et al. Attachment systems for mandibular implant overdentures: a systematic review. $J$ Adv Prosthodont. 2012;4(4):197-203.
29. Elsyad MA, Hegazy SA, Hammouda NI, et al. Chewing efficiency and electromyographic activity of masseter muscle with three designs of implant-supported mandibular overdentures. A cross-over study. Clin Oral Impl Res. 2014;25(6):742-748.

30. Xu Sun, Jun-Jiang Z, Jian Liao, et al. Masticatory efficiency and oral health-related quality of life with implant-retained mandibular over dentures. Saudi Med J. 2014;35(10):1195-1202.

31. Cheng T, Sun G, Huo J, et al. Patient satisfaction and masticatory efficiency of single implant-retained mandibular overdentures using the stud and magnetic attachments. J Dent. 2012;40(11):1018-1023.

32. Shady M, Emera R, Hegazy SA, et al. Bar Locator Versus Bar Clip Attachment for Implant Assisted Mandibular Overdenture. Dentistry. 2014;S2:006

33. Bilhan H, Geckili O, Mumcu E, et al. The influence of implant number and attachment type on maximum bite force of mandibular overdentures: a retrospective study. Gerodontology. 2012;29(2):e116-e120.

34. Ucankale M, Akoglu B, Ozkan Y, et al. The effect of different attachment systems with implant retained overdentures on maximum bite force and EMG. European college of gerodontology. 2012;29(1):24-29.

35. Bakke M, Holm B, Gotfredsen K. Masticatory Function and Patien Satisfaction with Implant-Supported Mandibular Overdentures: A Prospective 5-Year Study. Int J Prosthodont. 2002;15(6):575-581.

36. Mohamed Sobhy, Mohamed Abd-Elakher. Effect of Different Attachment Size on the Muscle Activity in Single Implant Retained Mandibular Over denture. Current Science International. 2012;2(1):18-20. 